\title{
Efficacy and safety of endoscopic dilatation in the management of esophageal strictures in children
}

\author{
Ahmed A. Al Sarkhy, MD, FRCPC, Anjum Saeed, MD, FCPS, Yassin H. Hamid, MD, Mona M. Al Asmi, MD, \\ Tariq I. Altokhais, MD, SF-PS, Anhar A. Ullah, MSc, Asaad M. Assiri, DCH,FRCP.
}

\begin{abstract}
الأهداف : لتقييم نتائج التوسيع بالمنظار لعلاج تضيقات المرى لدى الأطفال .

الطريقة : تم مراجعة وتحليل ملفات الأطفال الذين تقل أعمارهم عن

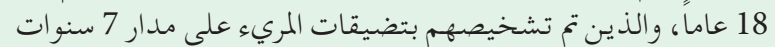

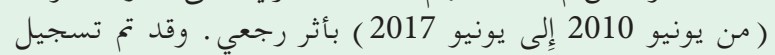

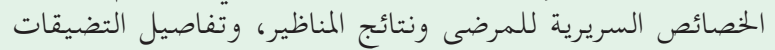

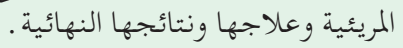

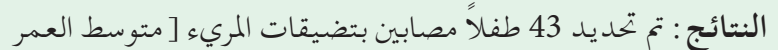

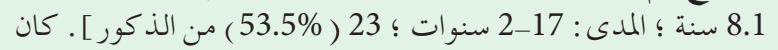

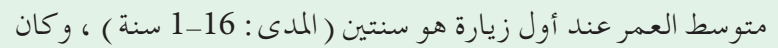

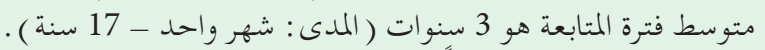

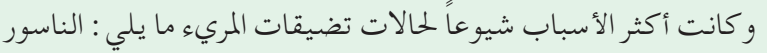

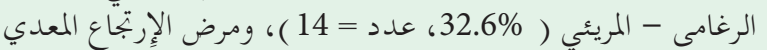

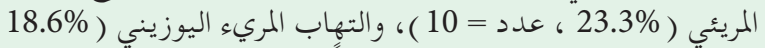

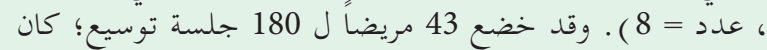

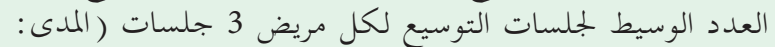

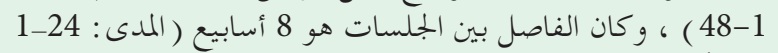

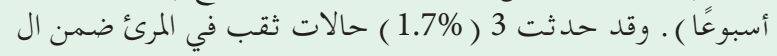

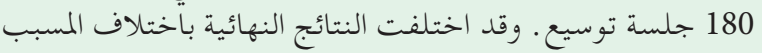

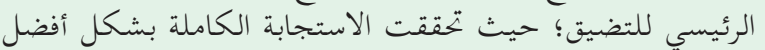
لدى حالات التهاب المريء اليوزيني ( - المريئي ( 71.4\%) ثم مرض الإرتجاع المعدي المريئي (70\% المبني (

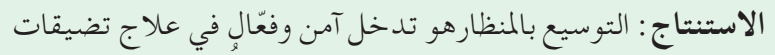

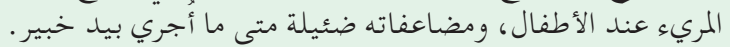

Objectives: To determine the outcomes of endoscopic dilatation of esophageal strictures in children.

Methods: Children younger than 18 years of age diagnosed with esophageal strictures over a period of 7 years (June 2010 to June 2017) were reviewed and analyzed retrospectively. The study took place at King Khalid University Hospital, Riyadh, Saudi Arabia. The patients' clinical characteristics, endoscopic findings, and details of the strictures, treatment, and outcomes were documented.

Results: Forty-three children with esophageal strictures were identified (median age, 8.1 years; range, 2-17 years; 23 [53.5\%] boys). The median age at presentation was 2 years (range, 1-16 years), and the median follow-up period was 3 years (range, one month-17 years). Tracheoesophageal fistula ( $n=14, \quad 32.6 \%)$, gastroesophageal reflux disease $(n=10,23.3 \%)$ and eosinophilic esophagitis $(n=8,18.6 \%)$ were the leading causes of esophageal strictures. Forty-three patients underwent 180 dilatation sessions; the median number of dilatation sessions per patient was 3 (range, 1-48), and the median interval between sessions was 8 weeks (range, 1-24 weeks). Among 180 dilatation sessions, 3 events $(1.7 \%)$ of esophageal perforation were observed. The outcomes varied depending on the primary cause of the stricture; complete response was achieved the best in eosinophilic esophagitis-related strictures (87.5\%), followed by anastomotic strictures post tracheoesophageal fistula repair $(71.4 \%)$ and gastroesophageal reflux disease-related strictures (70\%).

Conclusion: Endoscopic dilatation is a safe and effective intervention in the management of esophageal strictures in children, with minimal complications when conducted by experts.

Saudi Med J 2018; Vol. 39 (8): 787-791 doi: 10.15537/smj.2018.8.22845

From the Department of Pediatrics (Al Sarkhy, Assiri), Prince Abdullah Bin Khalid Celiac Disease Research Chair, College of Medicine; from the Department of Pediatrics (Al Sarkhy, Saeed, Hamid, Al Asmi, Assiri); from the Department of Surgery (Altokhais); from the Department of Cardiovascular Sciences (Ullah), King Saud University, Riyadh, Kingdom of Saudi Arabia, and from the Department of Pediatrics (Saeed). The Children's Hospital \& Institute of Child Health, Lahore, Pakistan.

Received 15th May 2018. Accepted 27th June 2018.

Address correspondence and reprint request to: Dr. Ahmed Al Sarkhy, Department of Pediatrics, Division of Gastroenterology, College of Medicine, King Saud University Medical City, King Saud University, Riyadh, Kingdom of Saudi Arabia. E-mail: aalsarkhy@ksu.edu.sa ORCID ID: orcid.org/0000-0002-1424-5784 
$\mathrm{E}$ sophageal strictures in children have various causes, among which gastroesophageal reflux disease (GERD), eosinophilic esophagitis (EoE), corrosive ingestion, congenital esophageal strictures (CES) and anastomotic strictures post tracheoesophageal fistula (TEF) repair. The clinical presentation is almost the same for all of these conditions: patients primarily present with dysphagia, recurrent vomiting, or food impaction. Esophageal perforation may be a presentation in some cases of corrosive ingestion. ${ }^{1,2}$ In addition to medical management, almost all patients with refractory esophageal strictures need either endoscopic dilatation or surgical intervention. Endoscopic dilatation can be performed using semi-rigid dilators (bougienage with or without guide-wire) or endoscopic balloon dilators (EBDs), which are increasingly being recognized as the treatment of choice in these cases. However, some physicians prefer to use semi-rigid dilators, particularly in the management of long strictures. ${ }^{3}$ The effectiveness of esophageal stricture dilatation can be checked directly through endoscopy (appearance of mucosal tearing at the stricture area) or indirectly through fluoroscopic study (disappearance of the stricture's waist). However, fluoroscopic-guided dilatation has the risk of radiation exposure, particularly in children. Surgical intervention is usually reserved for resistant types of esophageal strictures, such as long strictures and cases of congenital/structural defects. ${ }^{4,5}$ The present study aimed to determine the outcomes of endoscopic dilatation in the management of esophageal strictures in children.

Methods. This is a retrospective analysis of children diagnosed with esophageal strictures over a period of 7 years (June 2010 to June 2017) at a single tertiary care center, King Khalid University Hospital, Riyadh, Saudi Arabia All children younger than 18 years of age with esophageal strictures were included.

Data were retrieved from the patients' records, including demographics, clinical presentation, endoscopic findings, treatment of esophageal strictures, and outcomes. All patients underwent esophagogram contrast study before endoscopic dilatation to identify the location (proximal, middle, or distal esophagus), numbers (single versus multiple), and the length of the strictures (short segment $[<1$ vertebra $]$ versus

Disclosure. Authors have no conflict of interests, and the work was not supported or funded by any drug company. long segment $[\geq 1$ vertebra]). In addition, the type of dilator (balloon versus semi-rigid dilators), number of dilatation sessions along with the intervening intervals, and the duration of follow-up were also documented.

Dilatation procedures. Dilatation using EBDs or semi-rigid dilators was started at (a size) just larger than the stricture lumen size over an endoscopically inserted guide-wire, and it was then gradually increased by $3 \mathrm{~mm}$ per dilatation for a maximum of 3 increments in one session. The target was disappearance of the stricture's waist on fluoroscopic images. Appropriate positioning of the dilator at the waist of the stricture area was confirmed endoscopically or fluoroscopically. The dilator was kept in place for 1-1.5 min before proceeding to the next dilatation size (Figure 1). Patients with GERD and EoE continued to receive medical treatment for these conditions along with the dilatation intervention.

Outcomes. Clinical response was assessed according to the the degree of improvement in symptoms and the need for further dilatation. The response was considered complete if the symptoms resolved completely without the need for further dilatation; satisfactory if there was partial symptom improvement; and inadequate if there was no symptom improvement despite multiple dilatation sessions.

Statistical analysis. Mean and standard deviation were calculated for continuous variables while proportions for categorical variables. A $p$-value of $<0.05$ was considered statistically significant. The Statistical Analysis System (SAS) Version 9.2 (SAS Institute, Inc., Cary, NC) was used for statistical analysis of the data.

The protocol of this study was approved by the Institutional Review Board and Ethics Committee (IRB\# E-17-2485).

Results. Clinical characteristics of patients. A total of 43 children with esophageal strictures were identified over the study period (median age, 8.1 years; range, 2-17 years). Twenty-three $(53.5 \%)$ were males. The median age at presentation was 2 years (range, $1-16$ years) and the median follow-up period was 3 years (range, one month to 17 years).

The most common presentations are shown in Table 1. Post TEF repair (32.6\%, n=14), GERD (23.3\%, $\mathrm{n}=10)$ and $\mathrm{EoE}(18.6 \%, \mathrm{n}=8)$ were the leading causes of esophageal strictures in our patients. Other causes and features of esophageal strictures are shown in Table 1.

Management and outcomes of esophageal strictures. Under general anesthesia, EBD was the main modality utilized in our patients $(58.1 \%, \mathrm{n}=25)$, semi-rigid dilators with guide-wires (Savary-Gilliard bougies) 

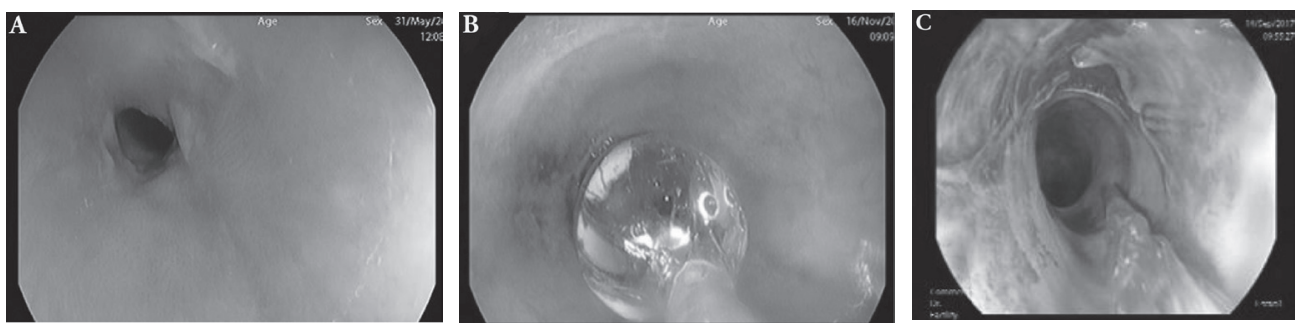

Figure 1 - Endoscopic balloon dilatation of an esophageal stricture. A) Pinhole appearance of the esophageal stricture. B) The balloon positioned endoscopically through the stricture. C) Post balloon dilatation view showing the increased diameter of the stricture which resulted in mucosal tear.

Table 1 - Characteristics of patients with esophageal strictures $(n=43)$.

\begin{tabular}{lrr}
\hline Characteristics & \multicolumn{3}{c}{ Outcomes } \\
& $\mathbf{n}$ & $(\%)$ \\
\hline Male & 23 & $(53.5)$ \\
Age (median) (years) & 8.1 & \\
Age at presentation (median) (years) & 2 & \\
Clinical presentation & & \\
$\quad$ Dysphagia & 33 & $(76.7)$ \\
Vomiting & 30 & $(69.8)$ \\
Food impaction & 6 & $(14.0)$ \\
Epigastric pain & 2 & $(4.7)$ \\
Foreign body impaction & 2 & $(4.7)$ \\
Primary etiology & & \\
Tracheoesophageal fistula & 14 & $(32.6)$ \\
Gastroesophageal reflux disease & 10 & $(23.3)$ \\
Eosinophilic esophagitis & 8 & $(18.6)$ \\
Achalasia & 5 & $(11.6)$ \\
Congenital esophageal stenosis & 4 & $(9.3)$ \\
Corrosive injury & 2 & $(4.7)$ \\
Length of stricture & & \\
Short segment & 38 & $(88.4)$ \\
Long segment & 5 & $(11.6)$ \\
Location of stricture & & \\
Distal & 15 & $(34.9)$ \\
Middle & 24 & $(55.8)$ \\
Proximal & 4 & $(9.3)$ \\
\hline & &
\end{tabular}

were used in 18 patients (41.9\%). Forty-three patients underwent 180 dilatation sessions. The median number of dilatation sessions per patient was 3 (range, 1-48), and the median interval between sessions was 8 weeks (range, 1-24 weeks).

The overall outcome showed achievement of a complete response in $67.4 \%$ and a satisfactory response in $30.2 \%$. The outcomes differed among the different causes; however, the best outcome (complete response) was achieved in EoE-related strictures (87.5\%), followed by anastomotic strictures post TEF repair (71.4\%) and GERD-related strictures (70\%). Details of the outcomes are shown in Table 2.

Surgical interventions were ultimately required in $14(32.6 \%)$ patients. This included 9 cases of post
TEF repair, one case of strictures post corrosive injury (planned for esophagectomy and gastric pull through after failure of stent placement), one case of congenital esophageal stenosis (resection of the stenotic segment with end to end anastomosis), and one case of achalasia (Heller myotomy). Further, 2 patients with GERDrelated strictures required adjuvant surgical intervention (fundoplication for associated hiatus hernia).

Strictures caused by caustic injury required a higher number of dilatation sessions (median $=27$; range, 6-48) to achieve a complete/satisfactory clinical response than strictures from other causes (CES: median=3.5, range, 2-6; achalasia: median=2, range, 1-3; GERD: median $=1.5$, range, $1-6$; EoE: median $=3.5$, range, 1-6), post TEF repair; median $=2.5$, range, $1-13$ ).

No adjuvant endoscopic topical therapy (namely, topical steroid injection or mitomycin $\mathrm{C}$ application) was used during the study period.

Out of the 180 dilatation procedures, only 3 events $(1.7 \%)$ of transmural esophageal leak were observed; 2 patients with TEF and one patient with CES. All of them occurred after using the semi-rigid dilators. The perforation healed spontaneously in all of them with conservative management using intravenous antibiotics, fasting, and total parenteral nutrition over 4 weeks, and these patients underwent an additional dilatation sessions without complications. No other types of complications, such as esophageal bleeding, infection, or chest pain were seen.

Discussion. Esophageal strictures are not an uncommon condition in children. The most common types are anastomotic strictures (post TEF repair), inflammatory strictures (secondary to GERD and EoE) followed by the strictures related to congenital anomalies and corrosive injury. In a study from Colombia that included 89 children, post-TEF repair strictures were reported in $57 \%$ of the cases, caustic injury strictures in $21 \%$ cases, GERD-related strictures in $12 \%$ cases 
Table 2 - Post-dilatation outcomes of esophageal strictures.

\begin{tabular}{|c|c|c|c|c|c|c|c|}
\hline \multirow[t]{2}{*}{ Diagnosis } & \multirow[t]{2}{*}{ Total } & \multicolumn{2}{|c|}{$\begin{array}{l}\text { Complete } \\
\text { response }\end{array}$} & \multicolumn{2}{|c|}{$\begin{array}{l}\text { Satisfactory } \\
\text { response }\end{array}$} & \multicolumn{2}{|c|}{$\begin{array}{l}\text { Inadequate } \\
\text { response }\end{array}$} \\
\hline & & $\mathbf{n}$ & $(\%)$ & $\mathrm{n}$ & $(\%)$ & $\mathbf{n}$ & $(\%)$ \\
\hline Eosinophilic esophagitis & 8 & 7 & $(87.5)$ & 1 & $(12.5)$ & 0 & $(0)$ \\
\hline Tracheoesophageal fistula & 14 & 10 & $(71.4)$ & 4 & $(28.6)$ & 0 & (0) \\
\hline Gastroesophageal reflux disease & 10 & 7 & $(70.0)$ & 3 & $(30.0)$ & 0 & (0) \\
\hline Achalasia & 5 & 3 & $(60.0)$ & 2 & $(40.0)$ & 0 & $(0)$ \\
\hline Congenital esophageal stenosis & 4 & 2 & $(50.0)$ & 1 & $(25.0)$ & 1 & $(25.0)$ \\
\hline Corrosive injury & 2 & 0 & $(0$ & 2 & $(100)$ & 0 & $(0)$ \\
\hline Total & 43 & 29 & $(67.4)$ & 13 & $(30.2)$ & 1 & (2.3) \\
\hline
\end{tabular}

and $9 \%$ cases included other causes. ${ }^{6}$ In a recent multicenter survey that included 106 Polish children with esophageal strictures, post-TEF repair strictures were the most common indication for esophageal dilatation (64\%), followed by caustic injury strictures in $16 \%$, then post-inflammatory strictures in $13 \% .^{7}$

In the present study, anastomotic strictures post TEF repair were the most common indication for esophageal dilatation $(32.6 \%)$, followed by inflammatory strictures secondary to GERD (23.3\%) and EoE (18.6\%). We had only 2 cases of post corrosive injury that account for only $5 \%$ of the cases. The median age of presentation in the present study was 2 years, which is consistent with the previous literatures (median, 2-3 years). ${ }^{7,8}$ However, the present study did not aim to determine the prevalence of esophageal strictures but rather to study the efficacy and safety of endoscopic dilatation in the management of these cases. Endoscopic dilatation is increasingly being recognized as the treatment of choice in managing patients with esophageal strictures. Use of semi-rigid dilators (with or without guide-wires) or EBDs depends on the stricture type, device availability, and the operator experience/preference. Endoscopic balloon dilator was the main modality utilized in our patients (58\%). Endoscopic balloon dilators have the advantage of applying a gradual uniform radial force on the stricture area unlike semi-rigid dilators, which tend to apply an abrupt shearing axial force that may increase the risk of esophageal trauma. Semi-rigid dilators were used in $42 \%$ of our cases because they work better for long strictures, readily available and less expensive compared to EBDs. Several studies have shown the superior effectiveness and safety of EBD compared to semi-rigid dilators, with an efficacy that ranges between $76 \%$ and $100 \%$, depending on the cause and criteria used to define effectiveness. $3,4,7,8$

In the present study, a median of 3 sessions per patient were needed to achieve a complete/satisfactory response, and the median interval between sessions was
8 weeks. Previous studies reported a median number of 2-5 dilatation sessions per patient to achieve a complete clinical response and an average intervals of 2-4 weeks between dilatation sessions. ${ }^{5,8}$ This variation is expected as the time interval between sessions depends on the initial stricture size, stricture resistance to dilatation, and clinical response to the previous session. ${ }^{9}$ Thus far, there is no consensus on the ideal protocol of endoscopic dilatation (frequency of sessions, time interval between sessions, and targeted lumen diameter). The frequency of dilatation and time interval between sessions depend primarily on the effect of the previous dilatation session and the degree of symptomatic improvement. ${ }^{9}$ Consistent with the findings of previous studies, we found that strictures secondary to caustic injuries required the highest number of dilatation sessions though they were only 2 cases. ${ }^{4,8,10,11}$ This is most likely related to the extensive fibrosis and scarring occurring after corrosive injuries. ${ }^{11}$

Gastroesophageal reflux disease-related strictures can be severe and difficult to manage, particularly in patients with a prolonged history of GERD. Pearson et al reported GERD-related strictures in $42 \%$ of their cohort of 115 children with esophageal strictures. ${ }^{12}$ Almost one quarter of our patients had GERD-related strictures, and 2-thirds of them showed a complete response after endoscopic dilatation, while the other third showed a satisfactory response. Previous studies reported successful outcomes approaching $80 \%$ in patients with GERD-related strictures.,11,13 In the present study, complete response was achieved in 70\% of the cases and satisfactory response in 30\%. Eighteen percent of our patients developed strictures secondary to EoE; complete response was achieved in $87.5 \%$ of the cases and satisfactory response was achieved in $12.5 \%$ cases. This is consistent with the previously reported studies in which endoscopic dilation of these cases was found to be very effective, with successful outcomes ranging between $75 \%$ and $100 \% .{ }^{14-16}$ Although adjuvant 
medical management for GERD and EoE could have contributed to their overall outcome, the primary efficacy of the dilatation itself on the final outcome may be indicated by the fact that the patients did not respond to the medical management prior to starting dilatation management. Congenital esophageal-related strictures are traditionally managed surgically, but increasing evidence suggests that endoscopic dilatation may be a safe and effective intervention, particularly in strictures caused by the fibro-muscular thickening subtype and membranous web subtype of CES. Surgical intervention is typically required in cases of tracheobronchial remnants (TBR) subtype. ${ }^{17-19}$ We had 3 cases from this category, only one of them required surgical intervention, the other 2 cases were managed endoscopically.

Esophageal perforation is a potential serious complication in patients with esophageal strictures. We had 3 events of esophageal perforation $(1.7 \%$ of the total number of dilatation sessions), all of them occurred after using semi-rigid dilators. Previous studies have shown that the risk of the perforation was higher when semi-rigid dilators were used (5-8\%) compared to the risk when EBDs were used (0.5-3\%). ${ }^{4-6}$ That is possibly due to the high shearing force exerted by the semi-rigid dilators. Long strictures caused by corrosive injury were reported to have a higher risk of perforation than those with other causes. ${ }^{5,8}$ Furthermore, the risk of perforation was reported to be higher in CES cases, especially after attempting dilation of TBR subtypes. ${ }^{9}$

The limitations of our study include its retrospective nature and the small sample size.

In conclusion, endoscopic dilatation is a safe procedure with minimal morbidity and mortality when conducted by expert hands. The risk of perforation is higher with semi-rigid dilators compared to the EBDs. However, the use of semi-rigid dilators or EBDs depends on several factors including the stricture type, device availability, and the operator experience/preference.

Acknowledgment. This research project was supported by King Saud University, Deanship of Scientific Research, Chair of Prince Abdullah bin Khaled Celiac Disease Research (PAK-CDRC), Riyadh, Saudi Arabia. We would like also to thank the Editage (www.editage.com) for English language editing.

\section{References}

1. Jones DW, Kunisaki SM, Teitelbaum DH, Spigland NA, Coran AG. Congenital esophageal stenosis: the differential diagnosis and management. Pediatr Surg Int 2010; 26: 547-551.

2. Spechler SJ. Clinical manifestations and esophageal complications of GERD. Am J Med Sci 2003; 326: 279-284.
3. Chang CF, Kuo SP, Lin HC, Chuang CC, Tsai TK, Wu SF, et al. Endoscopic balloon dilatation for esophageal strictures in children younger than 6 years: experience in a medical center. Pediatr Neonatol 2011; 52: 196-202.

4. Jayakrishnan VK, Wilkinson AG. Treatment of oesophageal strictures in children: a comparison of fluoroscopically guided balloon dilatation with surgical bouginage. Pediatr Radiol 2001; 31: 98-101.

5. Lan LC, Wong KK, Lin SC, Sprigg A, Clarke S, Johnson PR, et al. Endoscopic balloon dilatation of esophageal strictures in infants and children: 17 years' experience and a literature review. J Pediatr Surg 2003; 38: 1712-1715.

6. Cabrera Chamorro C, Méndez Manchola C, Molina Ramírez I, Perilla López M, Fierro Avila F. Endoscopic balloon dilatation of esophageal strictures in children. Cir Pediatr. 2013; 26: 106-111.

7. Pieczarkowski S, Woynarowski M, Landowski P, Wilk R, Daukszewicz A, Toporowska-Kowalska E, et al. Endoscopic therapy of oesophageal strictures in children - a multicentre study. Prz Gastroenterol 2016; 11: 194-199.

8. Alshammari J, Quesnel S, Pierrot S, Couloigner V. Endoscopic balloon dilatation of esophageal strictures in children. Int J Pediatr Otorhinolaryngol 2011; 75: 1376-1379.

9. Dall'Oglio L, Caldaro T, Foschia F, Faraci S, Federici di Abriola G, Rea F, et al. Endoscopic management of esophageal stenosis in children: New and traditional treatments. World J Gastrointest Endosc. 2016; 8: 212-219.

10. Uygun I, Arslan MS, Aydogdu B, Okur MH, Otcu S. Fluoroscopic balloon dilatation for caustic esophageal stricture in children: an 8-year experience. J Pediatr Surg 2013; 48: 2230-2234.

11. Saleem MM. Acquired oesophageal strictures in children: emphasis on the use of string-guided dilatations. Singapore Med J 2009; 50: 82-86.

12. Pearson EG, Downey EC, Barnhart DC, Scaife ER, Rollins $\mathrm{MD}$, Black RE, et al. Reflux esophageal stricture--a review of 30 years' experience in children. J Pediatr Surg 2010; 45: 2356-2360.

13. Numanoglu A, Millar AJ, Brown RA, Rode H. Gastroesophageal reflux strictures in children, management and outcome. Pediatr Surg Int 2005; 21: 631-634.

14. Al-Hussaini A. Savary dilation is safe and effective treatment for esophageal narrowing related to pediatric eosinophilic esophagitis. J Pediatr Gastroenterol Nutr 2016; 63: 474-480.

15. Ukleja A, Shiroky J, Agarwal A, Allende D. Esophageal dilations in eosinophilic esophagitis: a single center experience. World J Gastroenterol 2014; 20: 9549-9555.

16. Moawad FJ, Cheatham JG, DeZee KJ. Meta-analysis: the safety and efficacy of dilation in eosinophilic oesophagitis. Aliment Pharmacol Ther 2013; 38: 713-720.

17. Hu HT, Shin JH, Kim JH, Jang JK, Park JH, Kim TH, et al. Fluoroscopically guided large balloon dilatation for treating congenital esophageal stenosis in children. Jpn J Radiol 2015; 33: 418-423.

18. Elhalaby EA, Elbarbary MM, Hashish AA, Kaddah SN, Hamza AF, Waheeb SM, et al. Congenital esophageal stenosis: to dilate or to resect. Ann Pediatr Surg 2006; 2: 2-9.

19. Takamizawa S, Tsugawa C, Mouri N, Satoh S, Kanegawa K, Nishijima E, et al. Congenital esophageal stenosis: Therapeutic strategy based on etiology. J Pediatr Surg 2002; 37: 197-201. 